\title{
Construction of Nominal Ionospheric Gradient Using Satellite Pair Method Based on GNSS CORS Observation in Indonesia
}

slamet supriadi ( $\square$ asepslamet@yahoo.com )

Institut Teknologi Bandung https://orcid.org/0000-0001-9669-2264

Hasanuddin Zainal Abidin

Institut Teknologi Bandung

Dudy Darmawan Wijaya

Institut Teknologi Bandung

Prayitno Abadi

BRIN: National Reserach and Innovation Agency

Susumu Saito

ENRI: Electronic Navigation Research Institute

Dwiko Unggul Prabowo

BRIN: National Research and Innovation Agency

\section{Research Article}

Keywords: Ground-based augmentation system (GBAS), lonosphere, Nominal ionospheric gradient

Posted Date: January 10th, 2022

DOI: https://doi.org/10.21203/rs.3.rs-1220760/v1

License: (1) This work is licensed under a Creative Commons Attribution 4.0 International License.

Read Full License 


\section{Abstract}

Ground-Based Augmentation System (GBAS) is a GNSS augmentation system that meets International Civil Aviation Organization (ICAO) requirements to support precision approach and landing. GBAS is based on the local differential GNSS technique with reference stations located around the airport to provide necessary integrity and accuracy. The performance of the GBAS system can be affected by the gradient in the ionospheric delay between the aircraft and the reference stations. A nominal ionospheric gradient, which is bounded by a conservative error bound, is represented by a parameter $\sigma_{\text {vig. }} \cdot \sigma_{\text {vig }}$ was commonly determined using station pair to GNSS Continuous Operating Reference Station (CORS) data. The station pair method is susceptible to doubling of receiver bias error and is not suitable with the CORS conditions in Indonesia. We propose a satellite pair method that is found to be more suitable for the CORS network over Indonesia which is centered in Java and Sumatra islands. The value of $\sigma_{\text {vig }}(4.48$ $\mathrm{mm} / \mathrm{km}$ ) is obtained using this method along with the preliminary results of a comparison of $\sigma_{\text {vig }}$ from Java and Sumatra islands.

\section{Introduction}

The use of Global Navigation Satellite System (GNSS) for positioning and navigation has begun to be accepted by various modes of transportation. GNSS needs an augmentation to meet performance requirements for air navigation to maintain passenger safety[1]. Ground-Based Augmentation System (GBAS) is a system that augments GNSS to support precision approach and landing of aircraft.

GBAS is based on the range-domain differential GNSS technique to correct pseudorange errors at the user by measurements of reference stations of which precise positions are known. When a GNSS signal propagates through the ionosphere, the propagation is delayed and results in pseudorange error. The reference stations can estimate the error induced by the ionospheric delay together with other errors including tropospheric delay and satellite clock and ephemeris errors. The estimated errors are transmitted to users in the form of pseudorange correction. GBAS adds integrity information along with corrections that assure the integrity required for navigation systems on aircraft.

Spatial variations of the ionospheric delay or ionospheric gradient may degrade GBAS performance. Ionospheric gradient causes a difference in the value of the ionospheric delay between the reference station giving the correction and the user receiving the correction so that the error in the user's position may increase. lonospheric gradients that can interfere with GBAS performance are divided into nominal and anomalous. The nominal ionospheric gradient arises because the nature of the ionosphere is constantly changing. Therefore, the difference in ionospheric delay between the reference station and the user always exists. The anomalous ionospheric gradient is appeared infrequently due to space weather activity which results in a very large gradient value far exceeding its normal value.

The nominal value for Contiguous US (CONUS) is about $4 \mathrm{~mm} / \mathrm{km}[2]$ and the anomalous ionospheric gradient has more than $400 \mathrm{~mm} / \mathrm{km}[3]$. However, the magnitude of nominal gradient needs to be 
determined for each region. In GBAS, the nominal ionospheric gradient is characterized by the $\sigma_{\mathrm{vig}}$ parameter which is the conservative bound of the spatial gradient in the vertical ionospheric delay.

Research on GBAS is generally carried out in the mid-latitudes. Recently, research on GBAS in low latitudes is being intensively carried out. GBAS implementation in Indonesia is still in the initial study stage of GBAS Category I. GBAS CAT I is a GBAS that have the ability like ILS CAT I which provides guidance information from the coverage limit of the ILS to the point at which the localizer course line intersects the ILS glide path at a height of $60 \mathrm{~m}(200 \mathrm{ft})$ or less above the horizontal plane containing the threshold[1]. To meet the requirements for the application of GBAS Category I, it is necessary to determine the nominal value $\left(\sigma_{\mathrm{vig}}\right)$.

The parameter $\sigma_{\text {vig }}$ for CONUS is obtained by using ionosphere vertical delays data at each of two GNSS CORS stations that are differenced[2]. They used the ionospheric delay data generated from the reference receivers of the Wide-Area Augmentation System (WAAS) which is an implementation of Satellite-Based Augmentation System (SBAS) in United States. The use of continuously operated reference stations (CORS) data for $\sigma_{\text {vig }}$ was carried out in Germany [4] and Japan [5]. The analysis of the nominal ionospheric gradient in Japan was made for the east-west and north-south components of the gradients separately. The study concluded that there is a difference in the north-south direction with a larger southern ionospheric gradient as it is closer to low latitudes.

The distance between CORS stations is closer than the distance between SBAS reference stations so that it would better represent the gradient at a shorter distance relevant to GBAS. One of the software that can be used to calculate the ionospheric gradient using CORS data is the Long-Term lonospheric Anomaly Monitoring (LTIAM) tool [6].

Estimation of the ionospheric gradient in India has been carried out by using Indian SBAS (GPS-Aided GEO Augmented Navigation: GAGAN) data [7]. India is located in the low latitude region similar to Indonesia. The distance between the SBAS reference stations is so far that the calculation of the ionospheric gradient is carried out using the temporal decorrelation method. The temporal decorrelation method is useful because errors in the ionospheric delay estimates related to the inter-frequency bias estimation are canceled out. However, the results include the effects of relative motion between the gradient and the GNSS satellite. Research on ionospheric gradients in China was carried out using CORS data [8]. The ionospheric delay is obtained by slightly modifying the LTIAM algorithm by placing the cycle slip detection earlier.

Another sigma value search was conducted in Bangkok, Thailand using the time-step method on singlefrequency GPS [9]. The method is appropriate for Thailand's condition which most reference station distances are more than $20 \mathrm{~km}$. This is different from Indonesia where the number of CORS is getting denser. One of the weaknesses of the time step method is that the gradient obtained is the result of the difference between two IPPs with a north-south direction. Bangkok is located at $5^{\circ}$ North magnetic Equator while most of CORS in Indonesia is installed at $20^{\circ}$ South magnetic equator. 
Indonesia consists of many islands that are separated by the ocean where it is difficult to establish well distributed GNSS CORS network. Indonesia's CORS network at present consists of 280 CORS stations and is still not yet well distributed and mostly located on Java Island. The second center of the distribution is on Sumatra Island which is still near Java Island. Such distribution makes the station-pair methods could not be optimally applied in Indonesia. Additionally, Indonesia is located at low-latitudes geomagnetic which has high ionospheric dynamics which makes ionospheric delay estimation more challenging. This study investigates different methods to estimate $\sigma_{\text {vig }}$ suitable for the less dense CORS networks.

Determination of a suitable method will allow for further analysis of the difference in sigma values in the two CORS GNSS distribution centers.

\section{Data And Methodology}

The distribution of the CORS stations in Indonesia is mostly located on the island of Java until 2018. Distributions of the CORS stations are beginning to spread evenly across Sumatra Island by 2019. The distribution and corresponding ionospheric pierce points (IPPs) at an altitude of $350 \mathrm{~km}$ are shown in Figure 1. Available data on 1 January 2009 is around 18 stations and on 1 January 2019, it's increasing to 182 stations. We choose 1 January for this study because it is out of the seasons of ionospheric disturbances in this region which are March and September equinoxes.

The data processed are obtained when the ionosphere is in quiet condition, namely when the maximum $\mathrm{Kp}$ index is less than three. Kp index is an index that describes how geomagnetic activity in the earth's atmosphere. Data for 1 January 2014, 2016, 2017, and 2018 were not processed because geomagnetic activities were high (Kp>3). While the data for 2009, 2010, and 2011 were not processed because the number of data is not adequate for statistical analysis.

The distribution of CORS stations in Indonesia is getting denser year by year. The data on 1 January 2019 are used to analyze spatial ionospheric gradient because it is dense enough for the analysis. Spatial gradient analysis was carried out for the north-south or west-east directions with the CORS stations on Sumatra and Java Islands, respectively (Figure 2).

CORS data was processed using the LTIAM tool to calculate the slant ionospheric delay at the L1 frequency $(1.57542 \mathrm{GHz})$ along the satellite-receiver path. The slant ionospheric delays calculated by using pseudorange measurements at two frequencies include inter-frequency bias (IFB) associated with frequency-dependent hardware delays of satellite and receiver circuits. The LTIAM tool requires IONEX data containing global ionospheric delay data calculated using the global GNSS network of the International GNSS Service (IGS). The IONEX data also contains the satellite IFB data that can be used to estimate the ionospheric delay values.

The slant ionospheric delay for each satellite observed by each station is obtained by LTIAM software. LTIAM estimates a single receiver IFB using a simpler and faster method developed by [10], [11]. The 
vertical ionospheric delay (VID) at a height of $350 \mathrm{~km}$ is then calculated by dividing the slant ionospheric delay $(S I D)$ after IFBs are removed by the slant factor $(S F)$ as

$$
V I D=S I D / S F \quad[1]
$$

$$
S F(e l)=\frac{1}{\sqrt{1-\left(\frac{R \cos (e l)}{R+h s}\right)^{2}}}
$$

where $e /$ is the satellite elevation angle, $R$ is the earth radius, and $h s$ is the altitude where the IPPs are assumed at an altitude of $350 \mathrm{~km}$. The data obtained are filtered to exclude unsuccessful estimates of $V I D$ which is indicated by $V I D<0$. Vertical lonospheric Gradient $(V I G)$ is estimated by dividing a difference between a pair $(d l)$ of vertical ionospheric delays $\left(V I D_{1}, V I D_{2}\right)$ by the distance between the IPPs of each ionospheric delay $\left(d_{12}\right)$

$$
V I G=d I / d_{12}=\left(V I D_{1}-V I D_{2}\right) / d_{12}
$$

In this study, we compare the results of $\sigma_{\text {vig }}$ estimated by station pair, satellite pair, and mixed pair (Figure 3 ). First is the station pair method which takes differences between ionospheric delays observed by a pair of receivers with the same satellite. In this method, satellite IFB is canceled, but the error in receiver IFBs remains in the ionospheric delay differences. The second one, the satellite pair method, takes differences between ionospheric delays of a pair of satellites observed by the same receiver. In this method, receiver IFBs are canceled out. Though the error in satellite IFBs remains, the error of the satellite IFBs in IONEX data which are estimated by many receivers over the world would be smaller than the locally estimated receiver IFBs. The third one, the mixed pair method, takes differences between ionospheric delays at any pairs of IPPs regardless of which receiver and satellite the IPP originates from. The results of the mixed pair method are a combination of the station pair and satellite pair methods.

The calculation of Indonesia's nominal ionospheric gradient differs from other regions for two reasons. First, the distribution of CORS which is concentrated on the island of Java means that the IPP distance obtained is also limited. Second, the close CORS distance causes the ionospheric gradient at low distances to be susceptible to doubling of receiver bias error because the IPP distance as a divider is very low and the difference in ionospheric delay is divided which still contains receiver bias.

The probability distribution function (PDF) of the VIG occurrence is obtained with the estimated VIG values. Since the normal distribution with the raw standard deviation usually cannot bound all of the observed PDF, especially the tail of it, an inflation factor is multiplied to the raw standard deviation so that the normal distribution with the inflated standard deviation bounds the PDF down to a sufficiently low probability. The inflated standard deviation is adopted as $\sigma_{\text {vig. }}$.

\section{Results And Discussion}


Figure 4 shows the number of occurrences of ionospheric delay differences estimated by the three methods as a function of the IPP distance by a two-dimensional histogram. The left column shows the results of the mixed pair on a quiet day in four days $(01 / 01 / 2012,01 / 01 / 2013,01 / 01 / 2015$, and 01/01/2019). The two-dimensional histogram of observations number is a function of IPP separation and VID difference $(d l)$. The $x$-axis and $y$-axis show the bin division of the IPP separation and $d l$ respectively. The ideal maximum IPP separation distance for all available data is $500 \mathrm{~km}$. The color shows the number of observations per pixel.

The number of observations from the mixed pair method is greater than the others because this method processes all IPP pairs. $d /$ value is very large at low IPP separation distances, and it is difficult to determine what factors influence this condition. The middle column which is the result of the station pair has almost the same $d /$ value in every IPP separation. Ideally, the $d /$ value should be very small at low separation distances and bigger $d /$ at long separation distances as in satellite pair results (right column).

It can be seen that $d /$ estimated by the satellite pair and mixed pair methods are correlated with the IPP distance, while $d /$ estimated by the station pair method is not. It can be seen that large $d /$ values with short IPP distances in the mixed-pair method are mainly estimated by IPPs of station pairs. This can be understood that the receiver IFB errors in the station pair method become dominant in the short IPP distance cases. On the other hand, large $d /$ values at long distances in the results of the mixed pair methods are mainly by IPPs of satellite pairs. This could be because large IPP distances cases can be obtained by the satellite pair method.

Because $d /$ values estimated by the satellite pair method are well correlated with the IPP distance from short to long, the satellite pair method is considered to provide reliable $d /$ data down to short IPP distances. This is because the receiver IFB error is canceled in the satellite pair method and satellite IFB values in IONEX data are well estimated. Thus, it is suitable for areas of Indonesia. On the other hand, the satellite pair method would not be suitable in regions where the CORS distance is too far. The satellitepair method can be applied in the region where a moderately dense CORS network is available.

Table 1 Comparison of the value of the inflation factor $(f)$ and $\sigma_{\mathrm{vig}}$ in the unit of $\mathrm{mm} / \mathrm{km}$. 


\begin{tabular}{|c|c|c|c|c|c|c|c|c|}
\hline \multirow[t]{2}{*}{ Year } & \multicolumn{2}{|c|}{ Mixed-pair } & \multicolumn{2}{|c|}{ Station-pair } & \multicolumn{2}{|c|}{ Satellite-pair } & \multirow[b]{2}{*}{ Kp index } & \multirow[t]{2}{*}{ Data } \\
\hline & $F$ & $\sigma_{\text {vig }}$ & $F$ & $\sigma_{\mathrm{vig}}$ & $\mathbf{F}$ & $\sigma_{\mathrm{vig}}$ & & \\
\hline 2009 & - & - & - & - & - & - & 2.7 & insufficient \\
\hline 2010 & - & - & - & - & - & - & 1 & insufficient \\
\hline 2011 & - & - & - & - & - & - & 2 & insufficient \\
\hline 2012 & 1.6 & 6.65 & 2.2 & 4.55 & 1.3 & 4.38 & 1.7 & sufficient \\
\hline 2013 & 1.7 & 5.91 & 1.8 & 4.35 & 1.3 & 4.48 & 0.7 & sufficient \\
\hline 2014 & - & - & - & - & - & - & 3.7 & sufficient \\
\hline 2015 & 1.6 & 4.73 & 2 & 4.51 & 1.7 & 3.75 & 2.3 & sufficient \\
\hline 2016 & - & - & - & - & - & - & 6 & sufficient \\
\hline 2017 & - & - & - & - & - & - & 3.7 & sufficient \\
\hline 2018 & - & - & - & - & - & - & 3.7 & sufficient \\
\hline 2019 & 1.8 & 5.56 & 2 & 4.18 & 1.4 & 3.78 & 2.7 & sufficient \\
\hline
\end{tabular}

Table 1 shows the $\sigma_{\text {vig }}$ values estimated by the three methods in each year. The results of the satellite pair method show that the largest $\sigma_{\text {vig }}$ of $4.48 \mathrm{~mm} / \mathrm{km}$ is obtained in 2013. The peak solar activity was from 2013 to 2015. The small sigma value in 2019 was possible because it's in a period of solar minimum.

Figure 5 shows the probability density functions of VIG obtained by the three methods on 1 January 2013. These results show the advantages of the satellite pair (Figure 5c) method which has fewer tails because receiver IFB is canceled out in the satellite pair method. The tails of PDFs could be attributed to the large receiver bias and multipath. To prove this hypothesis, $d I$ and VIG values are simulated by the NeQuick model for the CORS over the Java region[12]. As expected, $d /$ values are well correlated with the IPP distance (Figure 6). The PDF of the VIG is smooth and the tail of the PDF is narrow. This is because it is a model which is free from measurement errors such as the IFB error or multipath errors as well as because the model represents the mean state of the ionosphere which is free from random day-to-day variability.

Table 2 shows the $\sigma_{\text {vig }}$ values at Sumatra and Java regions for data obtained in 2019 using the satellite pair method. The distributions of stations are different for Sumatra and Java regions. Note that Sumatra region has a wider range of latitudes and gradients may have more variability. $\sigma_{\text {vig }}$ in the Sumatra region has a slightly larger value than Java region. At first glance, this shows that there are no significant differences between the two regions. However, the range of latitude in Java region is narrower than in Sumatra. So, smaller variability is expected. But on the other hand, it is closer to the southern crest of the equatorial ionization anomaly (EIA), and the gradient may be larger. With these two competing effects, the resulting $\sigma_{\mathrm{vig}}$ of Java region may become similar to that of Sumatra region. Because only one day of 
data in 2019 is used for this comparison, this result is just one realization of the $\sigma_{\mathrm{vig}}$ characteristics which should be subject to the day-to-day variability of the background ionosphere. Therefore, further studies with more complete data must still be carried out to ensure whether the $\sigma_{\text {vig }}$ value can be applied to every airport in Indonesia or not.

\section{Table 2. The inflation factor $(f)$ and $\sigma_{\text {vig }}$ values in Sumatra and Java regions.}

\begin{tabular}{lll} 
Region & $\mathbf{F}$ & $\boldsymbol{\sigma}_{\text {vig }}$ \\
\hline Sumatra & 1.2 & $3.83 \mathrm{~mm} / \mathrm{km}$ \\
\hline Java & 1.5 & $3.75 \mathrm{~mm} / \mathrm{km}$ \\
\hline Indonesia (Sumatra \& Java) & 1.3 & $3.78 \mathrm{~mm} / \mathrm{km}$
\end{tabular}

\section{Conclusions}

Three methods, station pair, satellite pair, and mixed pair methods are used to evaluate the ionospheric delay gradients by using the data obtained by GNSS CORS networks over Indonesia on 4 quiet days in different years (01/01/2012, 01/01/2013, 01/01/2015, and 01/01/2019). The results of the station pair method appear to be contaminated by the receiver IFB errors for short IPP distances, which also impacts the results of the mixed pair method. The satellite pair method is found to be suitable for the GNSS CORS network over Indonesia and those with similar station densities.

The VIG values obtained by the satellite pair method had smoother PDF than those obtained by the other two methods. The largest ovig value obtained from available data by the satellite pair method was 4.48 $\mathrm{mm} / \mathrm{km}$ on 1 January 2013. A larger value of sigma may be found by adding more data and using a denser GNSS CORS network in the future. The value of ovig in Sumatra $(3.83 \mathrm{~mm} / \mathrm{km})$ is slightly higher than that of Java region $(3.75 \mathrm{~mm} / \mathrm{km})$. The small difference may be due to combined effects of different geographic distribution CORS stations (elongated in the east-west and north-south directions in Java and Sumatra regions, respectively) and different magnetic latitudes (closer to the southern EIA crest and magnetic equator for in Java and Sumatra regions, respectively) as well as the day-to-day variability of the background ionosphere. These results still require clarification with analysis by using more data.

\section{Abbreviations}

CAT I: Category I

CONUS: Contiguous United State

CORS: Continuous Operating Reference Station

EIA: Equatorial lonization Anomaly 
GBAS: Ground Based Augmentation System

GNSS: Global Navigation Satellite System

GPS: Global Positioning System

ICAO: International Civil Aviation Organization

IFB: Inter-Frequency Bias

IGS: International GNSS Service

IONEX: lonosphere Map Exchange

IPP: Ionosphere Pierce Point

LTIAM: Long-Term lonospheric Anomaly Monitoring

PDF: Probability Distribution Function

RINEX: The Receiver Independent Exchange

SBAS: Satellite Based Augmentation System

SID: Slant lonospheric Delay

SF: Slant Factor

VID: Vertical lonospheric Delay

VIG: Vertical Ionospheric Gradient.

\section{Declarations}

\section{Ethics approval and consent to participate}

Not applicable.

\section{Consent for publication}

Not applicable

\section{Availability of data and materials}

The IONEX data are available at the IGS website (https://www.igs.org). The analyzed TEC and VIG data can be obtained upon request to the corresponding author (asepslamet@yahoo.com). 


\section{Competing interests}

The authors declare that they have no competing interests.

\section{Funding}

This study in under degree by research program from National Institute Research and Innovation (BRIN), Indonesia.

\section{Authors' contributions}

SSupriadi designed this study and performed the analysis. HA, DD, and PA supported Slamet Supriadi to investigate spatial analysis and supervised the findings of this work. SSaito supported this analysis and contributed to the discussion. DU verified the analytical methods. All authors discussed the results and contributed to the final manuscript.

\section{Acknowledgements}

The authors would like to express their gratitude to Badan Informasi Geospasial (BIG) for providing their available RINEX observation data from 2009 to 2019 and Badan Pertanahan Nasional (BPN) for providing RINEX data from 2013 to 2015.

\section{Authors' information}

Slamet Supriadi is Ph.D. students in Geodesy and Geomatics Engineering from Bandung Institute of Technology. He has been involved in ionospheric research for GNSS applications since 2008 at National Institute of Aeronautics and Space (LAPAN) in Indonesia which is now transformed to National Institute for Research and Innovation (BRIN).

Hasanuddin Z. Abidin is the Professor at Bandung Institute of Technology (Institut Teknologi Bandung) Indonesia, in the field of Geodesy. Previously he is the Head (President) of Geospatial Information Agency (Badan Informasi Geospasial) of Indonesia during the period of Dec-2016 to August-2020. His current research interests are mainly related to GNSS Applications, Geospatial Information Infrastructure, and Natural Hazard Mitigation and Adaptation.

Dudy Darmawan Wijaya received his Ph.D. degree in Graz University of Technology, Austria in 2009. He is a Lecturer in Geodesy and Geomatics Engineering from Bandung Institute of Technology. His current research interests are mainly related GNSS Reflectrometry, Trophospheric measurement, PPP, and other Hazard Mitigation using GNSS applications

Prayitno Abadi received his Ph.D. degree in Electrical Engineering from Nagoya University, Japan in 2018. He has been involved in ionospheric scintillation and plasma bubble research since 2008 at LAPAN BRIN. 
Susumu Saito received his Ph.D. degree in Science from Nagoya University, Japan in 2001. He joined Electronic Navigation Research Institute (ENRI), Japan in 2008. He is involved as a Principal Researcher in a project to develop a ground-based augmentation system (GBAS) suitable for low-latitude regions.

Dwiko Unggul Prabowo received his Master Degree in Computer Engineering at Keimyung University in 2019. He has been involved in ionospheric research for GNSS applications since 2011 at LAPAN - BRIN.

\section{References}

[1] International Civil Aviation Organization (ICAO), "Annex 10 to the Convention on International Civil Aviation. Aeronautical Telecommunications, Amendment 90," no. November, 2016.

[2] J. Lee, S. Pullen, S. Datta-Barua, and P. Enge, "Assessment of nominal ionosphere spatial decorrelation for LAAS," Rec. - IEEE PLANS, Position Locat. Navig. Symp., vol. 2006, pp. 506-514, 2006.

[3] S. Pullen, Y. S. Park, and P. Enge, "Impact and mitigation of ionospheric anomalies on ground-based augmentation of GNSS," Radio Sci., vol. 44, no. November 2008, pp. 1-10, 2009.

[4] C. Mayer, B. Belabbas, N. Jakowski, M. Meurer, and W. Dunkel, "Ionosphere threat space model assessment for GBAS," 22nd Int. Tech. Meet. Satell. Div. Inst. Navig. 2009, ION GNSS 2009, vol. 1, no. October, pp. 217-225, 2009.

[5] T. Yoshihara, S. Saito, and N. Fujii, "A Study of Nominal lonospheric Gradient for GBAS (Groundbased Augmentation System) in Japan," Proc. 23rd Int. Tech. Meet. Satell. Div. Inst. Navig. (ION GNSS 2010), pp. 2689-2694, 2010.

[6] J. Lee, S. Jung, M. Kim, J. Seo, S. Pullen, and S. Close, "Results from automated ionospheric data analysis for Ground-Based Augmentation Systems (GBAS)," Inst. Navig. Int. Tech. Meet. 2012, ITM 2012, vol. 2, pp. 1451-1461, 2012.

[7] S. R. Ammana and S. D. Achanta, "Estimation of overbound on ionospheric spatial decorrelation over low-latitude region for ground-based augmentation systems," IET Radar, Sonar Navig., vol. 10, no. 3, pp. 637-645, 2016.

[8] Z. Wang, S. Wang, Y. Zhu, and P. Xin, "Assessment of lonospheric Gradient Impacts on GroundBased Augmentation System (GBAS) Data in Guangdong Province, China," Sensors 2017, 2017.

[9] J. Budtho, P. Supnithi, and S. Saito, "Single-Frequency Time-Step lonospheric Delay Gradient Estimation at Low-Latitude Stations," IEEE Access, vol. 8, pp. 201516-201526, 2020.

[10] G. Ma and T. Maruyama, "Derivation of TEC and estimation of instrumental biases from GEONET in Japan," Ann. Geophys., vol. 21, no. 10, pp. 2083-2093, 2003. 
[11] S. Jung and J. Lee, "Long-term ionospheric anomaly monitoring for ground based augmentation systems," Radio Sci., vol. 47, no. 4, pp. 1-12, 2012.

[12] B. Nava, P. Coïsson, and S. M. Radicella, "A new version of the NeQuick ionosphere electron density model," J. Atmos. Solar-Terrestrial Phys., vol. 70, no. 15, pp. 1856-1862, 2008.

\section{Figures}
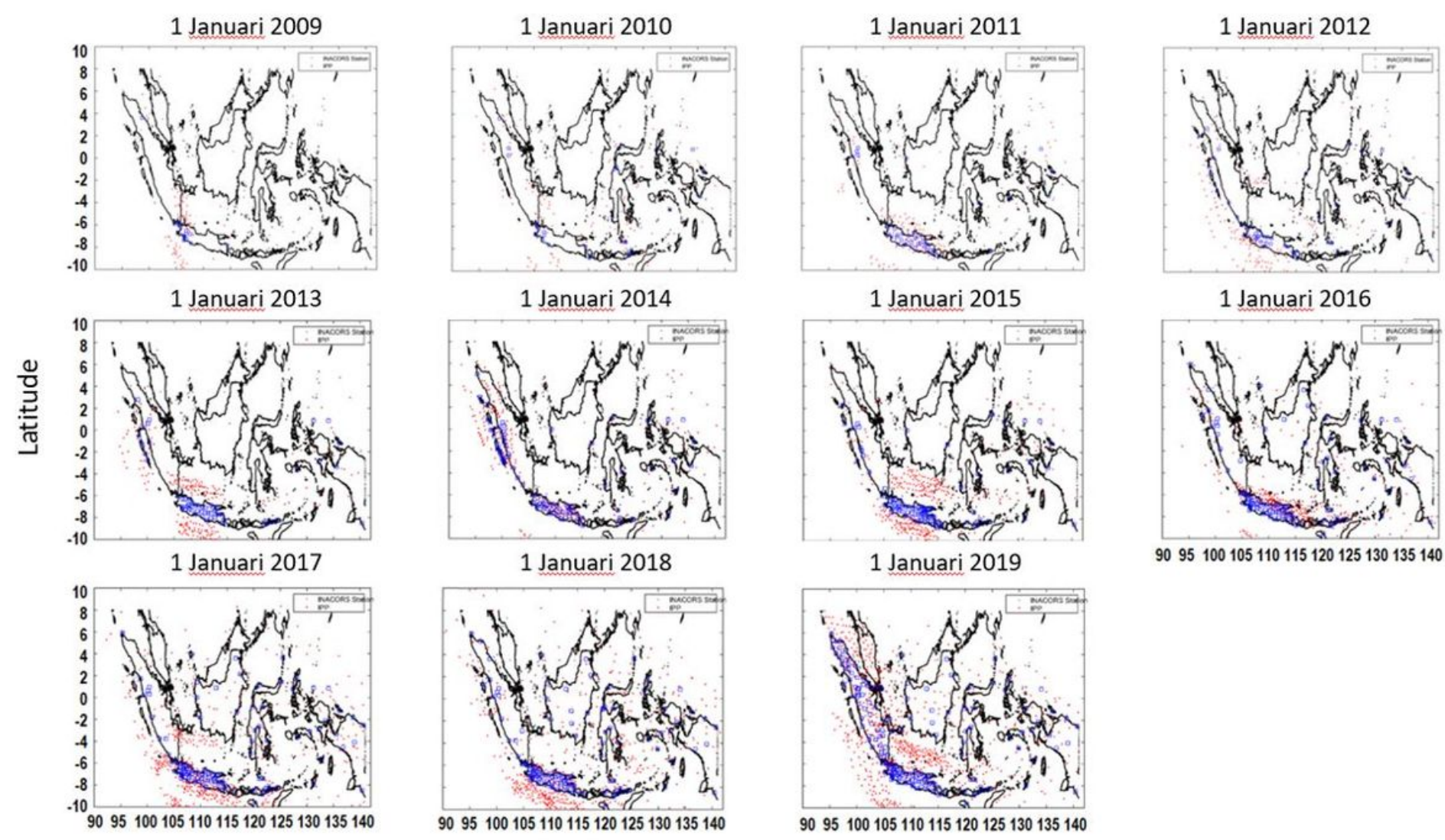

\section{Januari 2014}

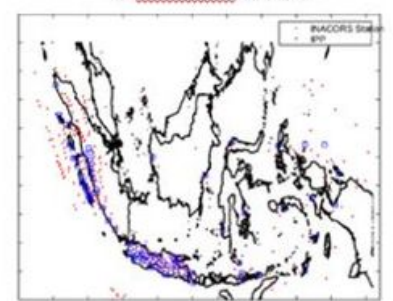

1 Januari 2018

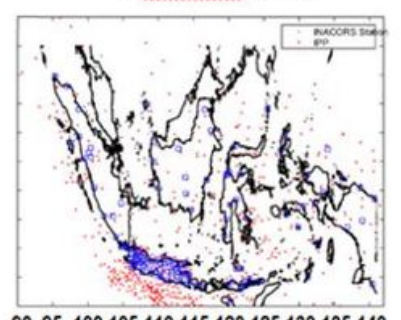

9095100105110115120125130135140 Longitude

\section{Januari 2015}

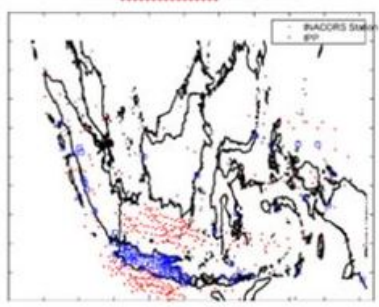

1 Januari 2019

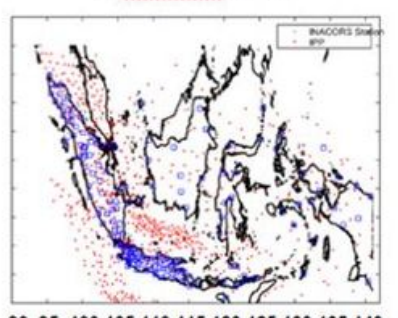

9095100105110115120125130135140
1 Januari 2016

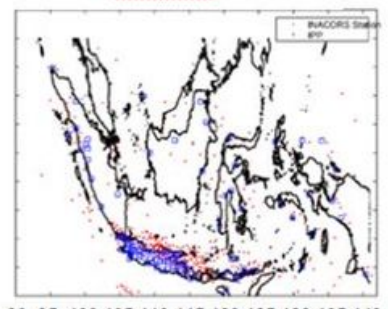

9095100105110115120125130135140

\section{Figure 1}

Distribution of CORS stations (blue) from 2009 to 2019 and their IPPs with an elevation angle of 30o (red) at 0 UT or 7 local time on 1 January in each year. 


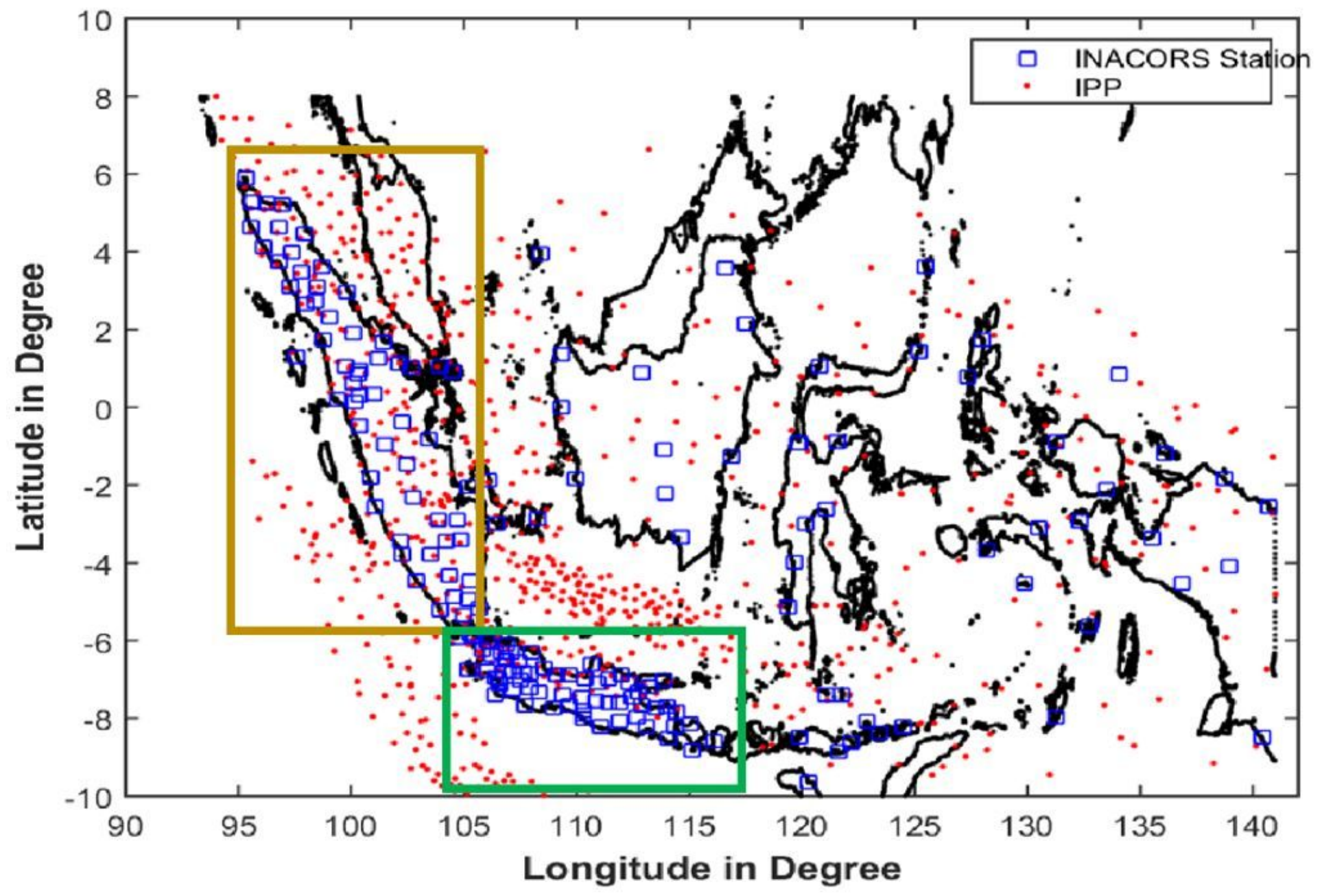

Figure 2

Distribution of CORS data on January 1,2019, for spatial analysis. Analysis of the Northwest-Southeast region using CORS data in Sumatra and Java. 


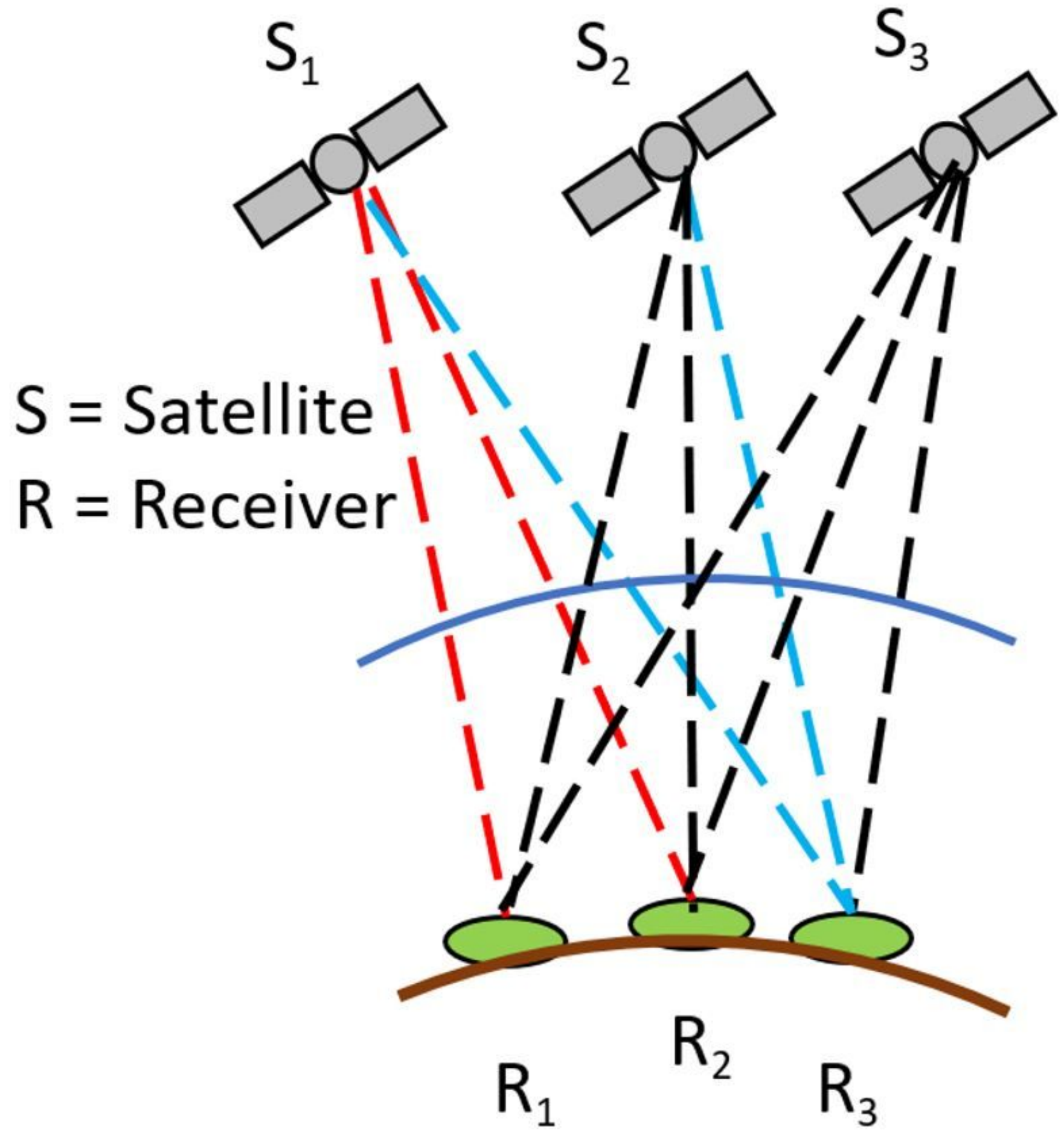

Figure 3

Mixed pair method (all colors) is a combination of station pair method (red dashed lines), and satellite pair (blue dashed lines). 


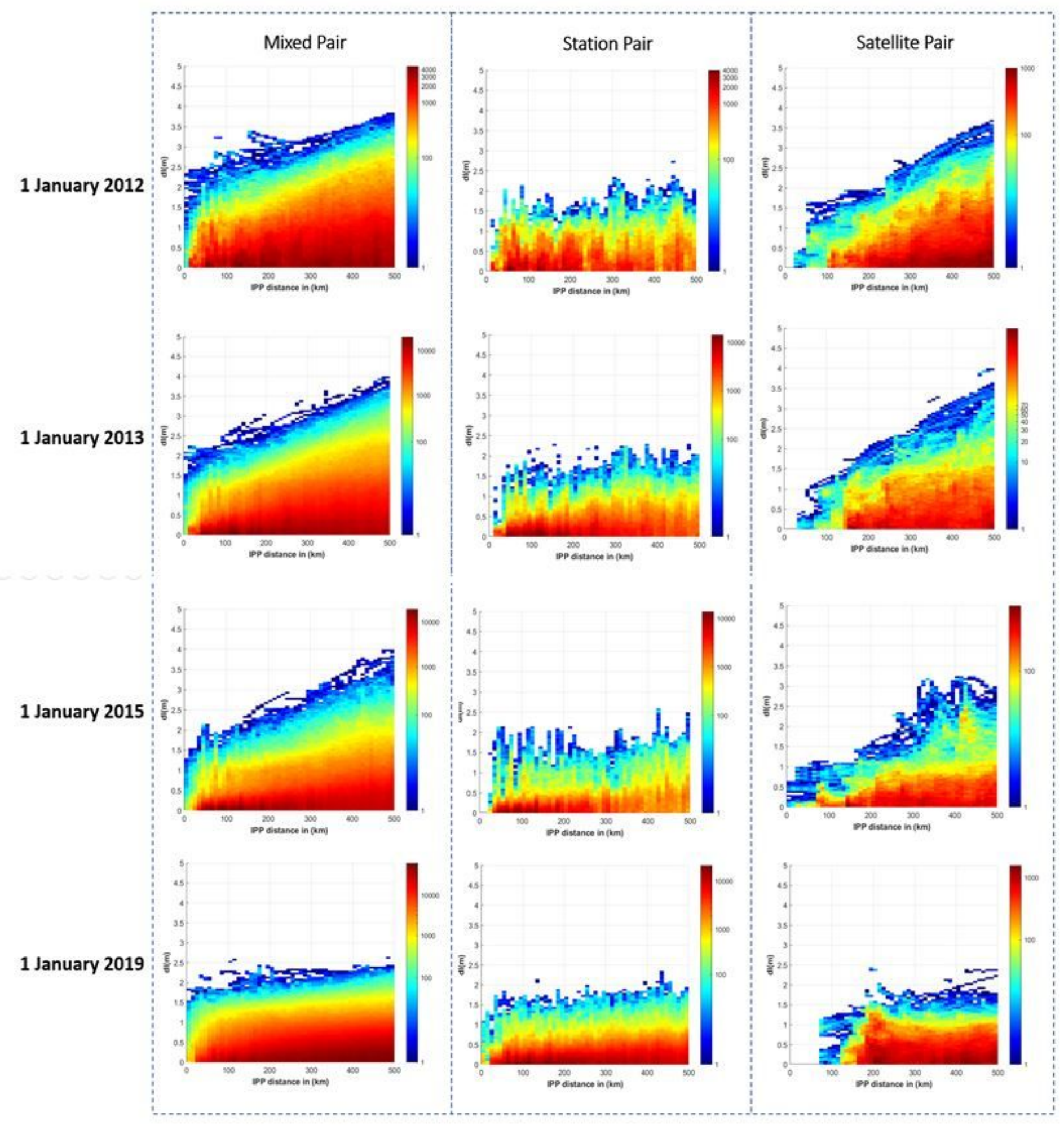

Figure 4

Occurrences of ionospheric delay differences as a function of the IPP distance estimated by the mixedpair, station-pair, and satellite-pair methods for 4 quiet days in different years. 
(a)

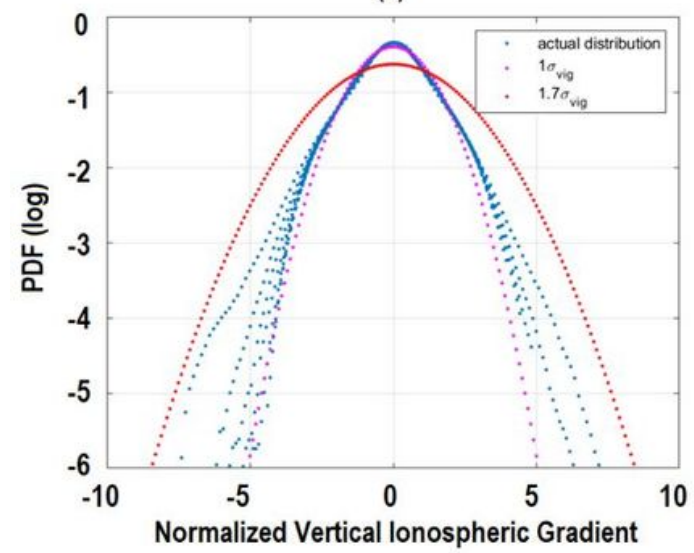

(b)

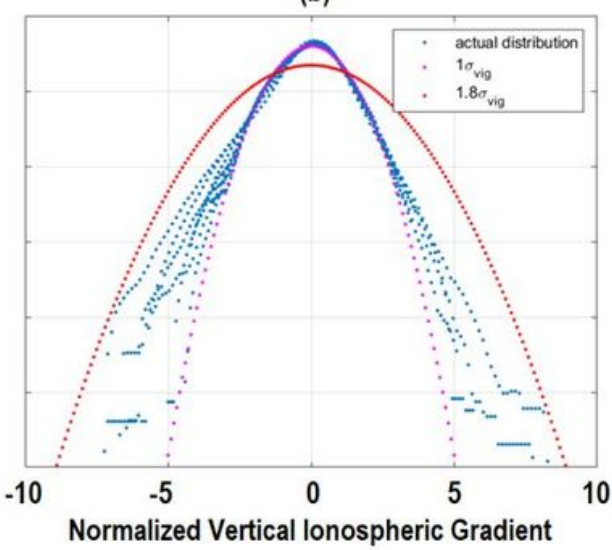

(c)

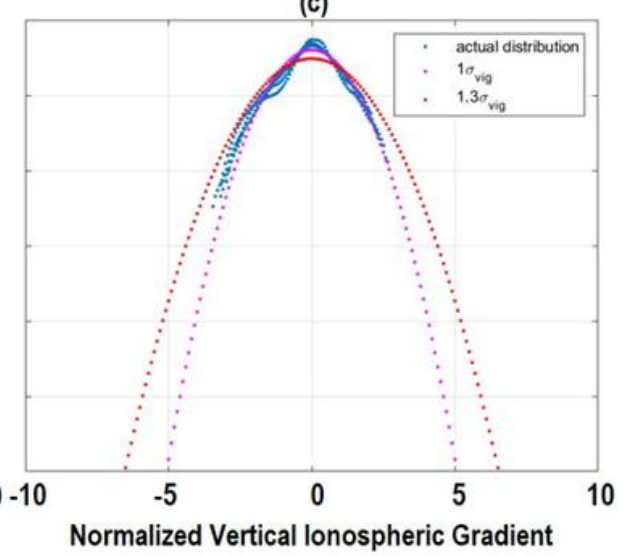

Figure 5

Probability density of the occurrence of the ionospheric gradients normalized by the raw standard deviation for the data on 1 January 2013 as a result of (a) mixed-pair, (b) station-pair, and (c) satellitepair.

(a)

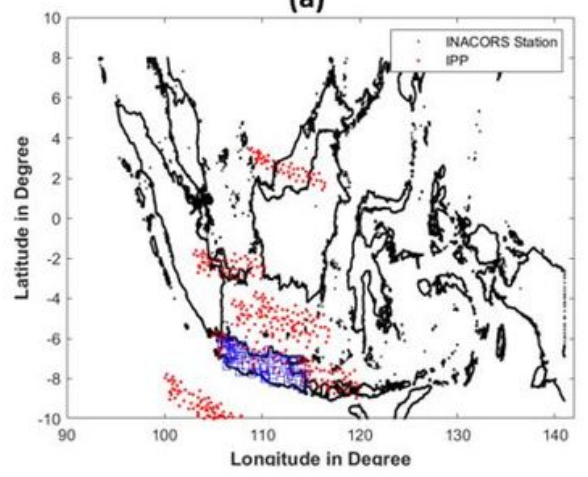

(b)

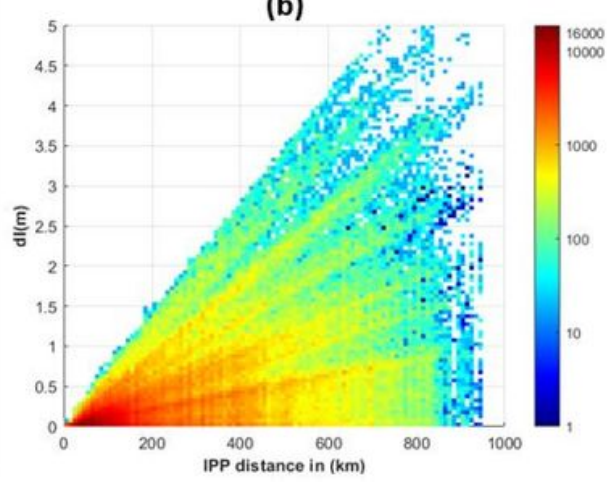

(c)

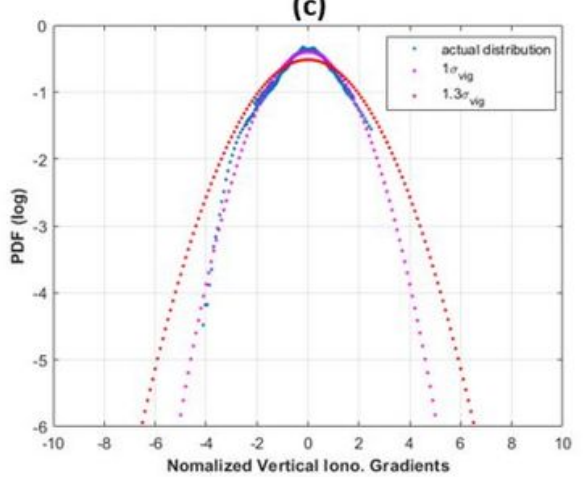

Figure 6

CORS location on Java island used in the NeQuick model, (b) ionospheric delay difference as a function of the IPP distance, (c) PDF of the normalized ionospheric gradient generated by the NeQuick model.

\section{Supplementary Files}

This is a list of supplementary files associated with this preprint. Click to download.

- abstract.jpg 